DOI: https://doi.org/10.30749/2594-8261.v3n1p197-213

\title{
IMPUNIDADES CRIMINOSAS, DE SOL DE CARVALHO: QUESTÕES CULTURAIS E ESTÉTICAS ${ }^{1}$
}

\section{CRIMINAL IMPUNITIES, OF SOL DE CARVALHO: CULTURAL AND AESTHETIC ISSUES}

Maria Geralda de Miranda*

Resumo: As desigualdades entre homens e mulheres, secularmente existentes, não surgiram como fruto da escolha destas últimas, mas são impostas por um processo histórico coercitivo que as institucionalizou como leis e normas e as insculpiu por meio da mitologia, da religião, da filosofia, da ideologia, da ciência e teoria do direito. $\mathrm{O}$ filme Impunidade Criminosas aborda exatamente a fragilidade, ou a duvidosa aceitação, desses pactos históricos e coercitivos de dominação da mulher, que com muita frequência é vítima da violência física e simbólica ${ }^{2}$, e por "fazer justiça com as próprias mãos" passam a condenadas pelo Estado. É o caso de Sara, personagem central de Sol de Carvalho, que mata o seu marido a pauladas e é condenada e encarcerada em um presídio em Maputo.Este trabalho, volta-se, primeiramente, para a temática da violência contra a mulher em Moçambique, país constituído por culturas autóctones de tradições patriarcais seculares; segue observando a ação dramática entre os vários planos do filme, a progressão narrativa, o suspense e o diálogo de personagens. E detém-se, por fim, na simbologia dos elementos místicos que "costuram" a ação narrativa entre os vários planos.

Palavras Chave: Cinema moçambicano. Violência contra a mulher. Culturapatriarcal.

Abstract: Age-old inequalities between men and women did not arise as a resultof the choice of the latter but were imposed by a coercive historical process that institutionalized them as laws and norms and instilled them through mythology, religion, philosophy, ideology, of science and theory of law. The film Criminal Impunity deals precisely with the fragility, or the dubious acceptance, of these historical and coercive pacts of domination of women, who very often are victims of physical and symbolic violence, and for "doing justice with their own hands" are condemned by State. This is the case of Sara, the central character of Sol de Carvalho, who kills her husband with beatings and is convicted and imprisoned in a prison in Maputo. This

\footnotetext{
1 Trabalho apresentado no XII Congresso da Associação internacional de Lusitnistas em julho de 2017, em Macau, China, sob o título de Impunidades Criminosas, de Sol de Carvalho: Cultura patriarcal em xeque.

"Pós-doutora em Políticas Públicas, Pesquisadora do Programa de Pós-graduação em Desenvolvimento Local, Centro Universitário Augusto Motta. E-mail: mgeraldamiranda@gmail.com.

${ }^{2}$ Sobre a violência simbólica, Bourdieu (2000, p. 124), diz que "lo que está enjuegoenlasbatallas simbólicas es laimposición de lavisiónlegítimadel mundo social y de tusdivisiones, esto es, el poder simbólico como poder constructordel mundo (...), el poder de inponer e inculcar los princípios de construcción de la realidade."
} 
work focuses first on the theme of violence against women in Mozambique, a country made up of indigenous cultures of secular patriarchal traditions; continues to observe the dramatic action between the various plans of the film, the narrative progression, the suspense and the dialog of characters. And it stops at last in the symbology of the mystical elements that "sew" the narrative action between the various planes.

Key Words: Mozambican cinema. Violence against women. Patriarchalculture. 


\section{INTRODUÇÃO}

O cinema realizado na África subsaariana já completou meio século de existência. Os seus produtores têm buscado revelar uma visão de suas próprias sociedades, longe dos estereótipos veiculados pelo cinema coloniais, ou pelos filmes de aventura europeus e mesmo norte-americanos. De modo evidente, esses produtores colocam em primeiro plano, no centro da ação dramática, mulheres africanas, jovens, esposas, mães e avós. E em razão disso, as personagens femininas desenhadas por esses cineastas são bem diferentes das geralmente veiculadas nos filmes europeus, principalmente da primeira metade do século XX.

Sol de Carvalho é um desses realizadores que, em Impunidades Criminosas (IMPUNIDADES..., 2012), por meio da protagonista Sara, interpretada por Esperança Naiene, trata da violência contra as mulheres em Moçambique, mostrando suas raízes, suas faces e também a "aflição" e a "ruína" que ela pode provocar no tecido social.

Como bem argumentou Santos (2011), sob formas que variam de acordo com o tempo e o lugar, as mulheres têm sido consideradas como seres, cuja humanidade é problemática (mais perigosa ou menos capaz), quando comparada com a dos homens.

\section{CULTURA PATRIARCAL E VIOLÊNCIA CONTRA A MULHER}

O conceito de violência contra a mulher não significa uma simples oposição à violência contra o homem. Cunha (2014) observa que ao se falar em violência contra a mulher, o que se deseja é remeter às relações patriarcais de gênero e à desproporcionalidade que elas estabelecem na relação de convívio e identidade entre os gêneros. A noção de gênero que é utilizada nesse trabalho representa uma categoria socialmente construída e que deriva de crenças, normas e valores predominantes numa época historicamente determinada a respeito dos homens e das mulheres, sendo a família, neste processo, um elemento fundamental na aprendizagem e perpetuação desses valores, normas e crenças.

São processos que, como ensina Nunes (2007, p. 34), as sociedades humanas "estabelecem como indicadores de feminidade e de masculinidade e que 
repercute, quer na construção social dos modos de ser mulher e de ser homem e na organização social [...], quer nos significados atribuídos à realidade social no seu conjunto". Tal reflexão mostra que gênero é uma categoria criada para demonstrar que a grande maioria das diferenças entre os sexos são construídas social e culturalmente, a partir de papéis sociais diferenciados que, na ordem patriarcal, criam polos de dominação e submissão.

Mas para entender as desigualdades culturais entre homens e mulheres em geral e entre homens e mulheres africanos, em particular, em conformidade com Diop (2015), é fundamental verificar as raízes dessa problemática não só no tempo, mas no espaço. O autor mostra que o patriarcado e o matriarcado possuem diferentes berços uma vez que, durante o I milênio antes da nossa era, muitos países de África já poderiam ser governados por mulheres, tal como a Etiópia pela rainha Candance, contemporânea de César Augusto, cujo prestígio foi tão elevado que todas as rainhas que lhe sucederam adotaram o seu nome. O Egito, por meio do mito da Deusa Mãe do trigo, criadora da verdura, senhora do pão, da cerveja e da abundância, exaltava religiosamente uma mulher ${ }^{3}$.

As populações da África Negra, entre outras as do Mali, do Senegal, do Ghana, as da antiga Bechuanalândia (atual Botswana), do Sul da África e os Bantu da África Central, ainda seguindo os estudos de Diop (2015), foram sempre matrilineares. Com a islamização, um fator externo e não um processo de evolução interna, a maior parte das populações, que na Idade Média eram matrilineares, tornaram-se aparentemente patrilineares.

Assim, as origens matriarcais africanas são atenuadas pela transformação e mudança paulatina para o patriarcado com base em fatores externos, assinalados,

\footnotetext{
${ }^{3}$ Kwononoka (2015) pontua que o casamento no Egito foi sempre monogâmico, exceto na família real e nos membros da corte. Mas com o passar do tempo, na África, passou-se a adotar uma forma de casamento polígamo em que um homem toma para si várias mulheres como esposas legais e legítimas, segundo o grau ou a natureza da sua fortuna. Segundo o autor, essa prática emergiu como um luxo, que foi transplantado na vida familiar e social. Mas observa que nas representações esculturais e pictóricas do antigo Egito, a monogamia popular é comprovada pelos numerosos casais representados. Contrariamente a essa forma de casamento monogâmico, verificada fora da "nobreza" do Egito, Diop (2015) mostra que no berço nórdico, a poligamia era comum na aristocracia germânica do tempo do Tácito, na Grécia, na época de Agamémnon, e em toda a Ásia. Fato que permite observar que, contrariamente ao que advogavam os evolucionistas, a monogamia não resulta da evolução da poligamia.
} 
por exemplo, pela penetração do Islamismo e do Cristianismo e pela presença temporária da Europa (colonialismo) em África. $\mathrm{O}$ africano islamizado é automaticamente dominado pelo regime patriarcal, sobretudo no que concerne à herança dos bens; o mesmo sucede com os cristãos, protestantes ou católicos, em que o domínio do homem é imposto. Outro elemento exógeno na configuração ou formatação de novos regimes de filiação foi a legislação colonial que tendia a atribuir um estatuto da herança por via patrilinear.

A violência contra a mulher em Moçambique, particularmente, em Maputo, que é palco da história contada e representada por Sol de Carvalho, tem aumentado significamente. Segundo a representante da ONU-MULHER, Florence Raes (VIOLÊNCIA... 2010), "pelo menos, duas em cada três mulheres sofrem de algum tipo de violência, baseada no gênero, no país, situação que exige uma urgente união de esforços para a reversão do cenário, principalmente em relação à rapariga nas famílias". A representante da ONU reconhece que o país avançou em termos de legislação, mas não na efetiva implementação de políticas voltadas para a solução do problema.

Como argumenta Taela (2006), a violência contra a mulher em Moçambique não foge à crença da superioridade masculina, na instituição de normas que tratam a mulher como propriedade do homem, nos costumes conjugais ligados à compra da mulher, nas expectativas sociais em relação a cada gênero e na aceitação da violência como forma de resolução de conflitos.

Os jornais moçambicanos impressos e onlines noticiam com frequência os crimes cometidos contra as mulheres em Moçambique, com destaque, obviamente, para mulheres das camadas mais privilegiadas da sociedade. $O$ fragmento que segue é bastante elucidativo: "O Tribunal Judicial da Cidade de Maputo condenou Rofino Licuco a três anos e quatro meses de prisão por agressão a Josina Machel, filha de Samora e Graça Machel, num ato que deixou a vítima cega de um olho". E continua: "Depois do caso de Josina Machel, a elite política moçambicana foi abalada pelo assassínio, em dezembro do ano passado, de Valentina Guebuza, filha do antigo presidente moçambicano Armando Guebuza, pelo marido, Zófimo Muiuane, na residência do casal em Maputo". (VIOLÊNCIA DOMÉSTICA... 2017) 
Após o relato da notícia, o texto da Agência Lusa enfatiza que "os casos de violência doméstica relacionados com duas das famílias mais influentes de Moçambique são vistos como um espelho da magnitude deste tipo de delito no país", uma vez que tais acontecimentos se incluem "nas estatísticas que apontam para uma subida significativa da violência doméstica em Moçambique, que está cada vez mais a ter as mulheres também como autoras e não apenas vítimas". (VIOLÊNCIA DOMÉSTICA... 2017)

Ora, é o caso da personagem Sara, protagonista de Impunidades criminosas (IMPUNIDADES..., 2012), que, após várias violências cometidas contra ela pelo marido (física e simbolicamente), ela o mata e joga o corpo em um terreno baldio nas proximidades do bairro onde residia.

\section{O FILME E SEU FAZER}

O cinema se define, preliminarmente, a partir de uma permanente tensão entre a narração e a performance, uma vez que utiliza códigos representacionais e códigos narrativos. Ao mesmo tempo em que mostra uma história, também a narra. $E$ faz isso por dois motivos: a capacidade da narrativa fílmica de transpor tempo e espaço diegéticos, "resultante da manipulação dos planos pela montagem, e a inserção do espectador dentro da cena, por meio da manipulação de pontos de vista (seja pela movimentação da câmera, seja pela mise-en-scène e pelos demais artifícios de construção do quadro)". (SILVA, 2007, p. 43).

Quando se discute o cinema africano, particularmente o realizado em países de Língua Portuguesa, essa tensão é bem trabalhada para produzir no espectador o efeito de aproximação. Em entrevista à Revista Mulemba (MIRANDA, 2015, pp. 21 28), o cineasta Sol de Carvalho disse que "os espectadores moçambicanos procuram uma relação de proximidade no cinema e que a proposta europeia da reflexão, dos heróis distanciados e racionais, não tem sucesso, até porque, à partida, estes são propositadamente complexos, racionais e distantes."

Em flash back, o filme Impunidades Criminosas (IMPUNIDADES..., 2012) começa com a personagem Sara em um presídio de Maputo, que, por meio de uma "câmera subjetiva" pensa sobre o acontecido, do momento em que cometeu o 
assassinato até ser presa e condenada. Ao pensar sobre sua prisão, ela elege uma interlocutora, a sua filha, a quem diz que gostaria que esta não sofresse o que ela, Sara, sofreu com o marido, interpretado por Bresnev Matezo.

$\mathrm{Na}$ verdade, o filme começa pelo fim da história (com a personagem na prisão), mas também não segue linearmente a narrativa do assassinato, relatado pela protagonista à sua interlocutora especial, a filha, que não aparece na ação cinematográfica, mas, segundo Sara, é a existência dela, da filha, que a leva a agir. A linearidade da diegese é quebrada por alguns elementos que vão se interpondo entre a história e a representação da protagonista, que é uma mulher comum da classe laborativa moçambicana, que trabalha no serviço doméstico em uma casa de família branca.

A família de Sara é composta por quatro pessoas: ela, o marido e dois filhos, um menino e uma menina. Os filhos estudam normalmente, são bem cuidados e a família não aparenta passar necessidades básicas de alimentação, moradia... A família mora em um subúrbio da grande cidade, Maputo, que como toda metrópole contemporânea possui engarrafamentos gigantescos, que Sara precisa atravessar para chegar ao trabalho. A protagonista tem dupla jornada, claramente representada, quando esta chega do trabalho e continua a trabalhar em casa.

O marido, por seu turno (a narração de Sara à sua interlocutora vai revelando) trabalhava para um grupo de "foras da lei", que dominava o território, onde a família morava e no período em que o esposo foi assassinado, ele estava devendo dinheiro ao chefe do grupo e, em razão disso, estava sendo pressionado a pagar. A complicação da história acontece quando o chefe do bando descobre que foi Sara quem matou o marido, tirando deste a decisão sobre a vida e a morte das pessoas do grupo chefiado por ele.

Após cometer o crime de assassinato, antes de ser presa, Sara passa a ser perseguida pela polícia (que dela passou a suspeitar) e pelo chefe do grupo de "foras da lei", ao qual o marido pertencia e estava "inadimplente" com o chefe.

O chefe diante da certeza de que Sara havia praticado o crime (o corpo foi encontrado em um terreno baldio e sem a cabeça) passou a exigir obrigações sexuais da protagonista, com argumentos embasados na tradição patriarcal da prática da kutchinga. Alegava que no bando todos eram irmãos e que Sara, em decorrência 
disso, era sua cunhada, sobre a qual ele tinha direitos sexuais em razão da morte do "irmão".

No romance "Niketche: uma história de poligamia", da escritora moçambicana Paulina Chiziane, a protagonista Rami explica o significado da prática da kutchinga: "é o direito de inaugurar a viúva na nova vida, oito dias depois da fatalidade. Kutchinga é carimbo, marca de propriedade. Mulher é lobolada com dinheiro e gado. É propriedade. Quem investe cobra, é preciso que o investimento renda". (CHIZIANE, 2004, p. 212)

O filme de sol de Carvalho não mostra diretamente a prática do lobolo, ou lovolo ${ }^{4}$, mas a reivindicação, por parte do chefe da gangue, da kutchinga, que é uma prática que decorre da outra (lobolo), conforme muito bem definiu Paulina Chiziane, por meio de sua personagem Rami.

O que é contado e representado no filme, primeiramente, é a "gota d'água" de Sara, que cansada da violência (física e simbólica) mata o marido. Há uma "inversão", ou uma "revidação" por parte da personagem, que de forma planejada, ou não, decide matar o cônjuge.

\subsection{Personagens e ação dramática}

Vanoye e Goliot-Lété (1994, p. 15) ensinam que para estudar um filme é necessário decompô-lo em seus elementos constitutivos para tornar visível "matérias que não se percebem isoladamente 'a olho nu', pois se é tomado pela totalidade". Parte-se, portanto, do texto fílmico para 'desconstruí-lo' e obter um conjunto de

\footnotetext{
${ }^{4}$ O lovoloé entendido como a compensação pela saída da noiva do seu grupo para o grupo do marido e pode ser constituído por enxadas, bois, dinheiro ou outros bens. O costume do lovoloé o reflexo do tabu do incesto, que compeliu os irmãos e as irmãs a procurarem os seus pares sexuais fora do grupo consanguíneo, sendo certo que os homens então se viram obrigados a assaltar as casas alheias para raptarem mulheres e como nas suas próprias casas acontecia precisamente o mesmo com as suas irmãs, este sistema transformou-se em preceito jurídico. Este processo levou à instauração de um estado de instabilidade social, de anarquia e de ausência de paz. Com efeito, para superar tal estado de coisas e restaurar a paz, em vez do rapto estabeleceu-se uma outra prática mais conciliatória e pacífica: a aquisição da mulher por compra, único meio de compensar a sua família pela perda de um dos seus membros. Instituía-se, assim, pela compra da mulher, a prática do lovolo. (Tomás, 2016, p. 101)
} 
elementos distintos do próprio filme, para, em seguida, estabelecer elos entre esses elementos isolados com vistas á reconstrução do filme.

Pinto (2008, p. 2019), estudioso das relações entre sociedade, ciência e técnica, considera que a tecnologia se sustenta em quatro significados fundantes 5 . Interessa nesse trabalho principalmente o quarto significado que se ampara no que ele denominou de "a ideologia da técnica", que é o modo pelo qual a tecnologia pode atuar na mediação de relações sociais, alterando inclusive seus fundamentos". Acredita-se que tal significado ajuda a pensar o cinema de Sol de Carvalho.

$\mathrm{Na}$ verdade, as histórias são contadas no cinema, por meio de códigos representacionais (a fotografia, a música, o texto...) encenações de atores, estrutura cênica, e de códigos narrativos (mise-en-scène, narrador fílmico, flexibilidade espaçotemporal da câmera). Como diz Hall (1997) "representação significa usar a linguagem para dizer algo significativo sobre, ou para representar o mundo de forma significativa para outras pessoas." O cinema torna possível dizer algo sobre o mundo: questionálo, reconstrui-lo, particulariza-lo, reinventá-lo... E permite mostrar esse algo para mais pessoas em diferentes espaços, porque a sua linguagem, formada por vários códigos, tem na imagem fotográfica (icônica por natureza) a sua "expressão narrativa" singular.

Ora, Impunidades Criminosas (IMPUNIDADES..., 2012) mostra esse "algo mais" para o mundo, porque aborda um tema universal, a violência contra as mulheres, mas algo muito "significativo" e particular para Moçambique.

Assim, a ação dramática do fime que conta a história de Sara pode ser dividida em três momentos: o primeiro constitui-se nos planos em que a personagem recorda a noite do assassinato do marido, que inclui as cenas em que o cônjuge senta-se em frente ao poço dos crocodilos e as cenas em que ela carrega o cadaver e joga no terreno baldio.

\footnotetext{
${ }^{5}$ Segundo Vieira Pinto (2005), o primeiro significado inclui a "teoria, a ciência, o estudo, a discussão da técnica, abrangidas nesta última noção as artes, as habilidades do fazer, as profissões e, generalizadamente, os modos de produzir alguma coisa.". O segundo está amparado pura e simplesmente na técnica, da forma como se apresenta no discurso habitual, senso comum, equiparada verbalmente à tecnologia. O terceiro significado tem a ver com "o conjunto de todas as técnicas de que dispõe uma determinada sociedade, em qualquer fase histórica de seu desenvolvimento", em que o conceito emerge do contexto social, ganha "generalidade formal", e se define como patrimônio, mas também, como instrumento de dominação - diferenciação e exclusão.
} 
A segunda constitui-se nas cenas de investigação do chefe do bando, a quem o marido de Sara devia dinheiro, que ao perceber que este último havia desaparecido, passa a persegui-la. As cenas em que aparece a investigação policial e a relação dos "homens da lei" com os bandidos, bem como as investidas sexuais do chefe do bando e a fuga de Sara para a aldeia, onde vivem seus parentes.

$\mathrm{Na}$ aldeia, a personagem passa a trabalhar na terra, juntamente com outras mulheres, mas nem lá fica livre do chefe, que a cerca de todas as maneiras, exigindo a consumação da prática da kutchinga, alegando que sua posição era de "irmão" do falecido e em razão disso, tinha direito sexuais em relação a ela.

O clímax do filme não acontece na conjunção dos elementos da investigação, mas na exigência e na consumação da kutchinga, prática sexual da cultura patriarcal, que secularmente impôs a supremacia masculina. Sara foi praticamente estuprada pelo chefe do bando, que também a queria como cozinheira.

Sara matou o marido para ficar livre da violência física e simbólica, mas a exigência da kutchinga era uma agressão da qual ela não conseguiu escapar. A carga dramática das cenas dela com o chefe do bando faz com que o espectador se identifique com a sua dor e, praticamente, a absolva do crime de assassinato.

$\mathrm{Na}$ terceira parte, entram as cenas relativas ao pós-clímax, que vão desde a realização da kuthinga até a prisão da personagem. Mas a articulação da ação dramática entre os vários planos do filme é realizada pela simbologia presente nos elementos místicos como a aliança, que teima em voltar para a protagonista Sara, os crocodilos que são adquiridos pelo seu consorte e pela presença da personagem sem nome, interpretada por Lucrecia Paco, que vê Sara desfazer-se do cadáver do esposo.

A personagem feminina, interpretada por Lucrecia Paco, não tem nome, nem participa da diegese propriamente dita. Aparece poucas vezes no filme, mas toda vez que entra em cena assume uma voz a questionar, ou a "justificar" aquele crime. Aparece pela primeira vez, quando Sara está carregando o corpo do marido. Em vários momentos ela entoa uma canção com uma melodia triste, cuja letra diz: "bateu, bateu...; bateu, bateu...; "bateu, bateu...; bateu, bateu...". 


\subsection{Os elementos místicos e os suspenses}

Os elementos místicos presentes nahistória são fundamentais, porque a enriquecem esteticamente o filme, que é uma obra feita com muita criatividade: da narração em flash back até o suspense provocado pela presença do "feiticeiro" na prisão. Tal personagem é o "orientador" espiritual de Sara, que o recebe já quase no final do filme, em cujas cenas, sem diálogos, se vê a força simbólica do "mundo espiritual" no filme de Sol de Carvalho. Tais elementos funcionam como uma segunda mensagem não explícita, mas que está ali, guiando a ação "linear" do filme, costurando os seus planos com vistas ao resultado almejado pelo produtor.

Já a presença da personagem interpretada por Lucrecia Paco, a costurar a ação dramática, faz pensar na presença de uma possível metáfora do coro da tragédia clássica, que na Grécia antiga, designava um grupo de dançarinos e cantores usando máscaras que participavam ativamente nas festividades religiosas e nas representações teatrais. Na tragédia clássica, o coro era uma personagem coletiva que tinha a missão de cantar partes significativas do drama. Na origem representava a polis, a cidade-estado, ampliando a ação para além do conflito individual ${ }^{6}$. De início, o texto do coro constituía a parte principal do drama, ao qual se interpolavam monólogos e diálogos. (SOUSA, 2005).

Em apenas uma cena, a personagem "misteriosa" (interpretada por Paco) simula a violência do homem contra a mulher. Com um cinto na mão, ela bate em uma árvore e, com a sofreguidão de quem apanhou, ela repete as palavras: "não", "não", "não". A sua voz faz eco para além do conflito individual entre Sara e o marido. É a voz a denunciar a impunidade dos que batem, humilham e até matam as mulheres e permanecem impunes. Fica implícito em sua voz e em seus gestos, que foi a cultura

\footnotetext{
${ }^{6}$ Sobre a unidade do couro, Sousa (2005) a unidade com que o coro se apresenta é óbvia nas várias obras trágicas que conhecemos, seja de Esquilo e Sófocles, seja de Eurípedes. Não apenas por se apresentar como uma das personagens, mas porque funciona como um todo que engendra em si todo o caráter e função de uma só vez em blocos nos pensamentos, conselhos e atos praticados. O coro tem em si a força da unidade e quando faz as suas intervenções parece representar um determinado grupo social (jovens, velhos, mulheres, escravos).
} 
da supremacia masculina, patriarcal, secularmente rearranjada, repaginada, reeditada na sociedade Moçambicana, que levou Sara a cometer o crime de assassinato.

É nesse aspecto que sua voz se parece com a voz de um possível coro a enunciar e anunciar que a situação de violência contra a mulher (e sua contra face, as violências geradas a partir daí, como a violência contra homens, como a praticada por Sara), propiciada pela cultura patriarcal não cabe mais naquela sociedade.

Mas a mulher e a sua voz podem ser lidas também como símbolos a representar o pensamento animista profundamente enraizado na cultura moçambicana. Como diz o cineasta Sol de Carvalho em entrevista à Revista Mulemba (MIRANDA, 2015 p. 27-28): “a existência do 'realismo fantástico' em países recentemente independentes é quase uma evidência. Dificilmente consigo ver um cinema africano e uma estética africana sem serem habitados por esses signos e pelas lógicas que o mundo espiritual exerce nas pessoas".

No decorrer da ação dramática, principalmente quando Sara está sendo ameaçada por homens do bando, ela é "visitada" pelo espírito do marido que insiste em não sair da casa. A personagem feminina "misteriosa" diz que ela precisa matar o marido no coração, para se livrar dele: ela havia matado o corpo, faltava matar o espírito... Em razão disso, Sara joga a aliança no poço dos crocodilos, mas a aliança, que deveria ter sido triturada aparece outras vezes intacta.

O crocodilo, segundo Chevalier e Gheerbrant (1982, pp. 305-6), cuja voracidade é a mesma da noite devorando o sol, ou de uma civilização a outra, ou de uma época a outra, se situa nas inumeráveis cadeias simbólicos da duplicidade em diversas culturas. O fundamental é que é uma força que domina a morte e o renascimento. Sua posição de intermediário entre os elementos terra e água faz do crocodilo o símbolo das contradições fundamentais.

Os crocodilos presentes no filme de Sol de Carvalho marcam a finitude do marido de Sara e uma nova vida para esta, muito diferente da que ela levava. Mas Impunidades criminosas (IMPUNIDADES..., 2012) não deseja apenas representar o conflito individual de Sara, logo, os crocodilos podem simbolizar um basta à violência proporcionada pela cultura da desigualdade de poder entre homens e mulheres, que vivem numa relação conjugal formal, com contrato jurídico, ou não. 
Conforme Tomás (2016), o emprego da violência masculina para controlar as mulheres tem sido historicamente desculpado, consentido e acatado pela maioria das instituições sociais; ou ainda que a dominação patriarcal justifica o uso da força, da hierarquização da relação conjugal e leva a mulher a se conformar com uma moralidade que a silencia e a culpa pela sua vitimização.

São as impunidades históricas que levou Sara a cometer o crime de assassinato: a fazer justiça com as próprias mãos. Rigorosamente o crime cometido por Sara foi ocasionado também pela impunidade dos violentadores de mulheres e pelas práticas culturais seculares, que oprimem a mulher: lobolo, kutchinga, poligamia e a aceitação da pratica diferenciada de gêneros em Moçambique.

Como mostra Chiziane: "poligamia é poder, porque é bom ser patriarca e dominar, (...) uma mulher para cozinhar, outra para lavar os pés, (...) outra para passar a noite. Ter reprodutoras de mão-de-obra, para as pastagens e gado, para os campos de cereais (...) pelo simples facto de ter nascido homem”. (Chiziane, 2004, p. 92).

A trágica e violenta história do filme tem sua "justificação", na cultura patriarcal secular, que trata a mulher com violência todos os dias, inclusive quando deixa os violentadores impunes. É certo afirmar, todavia, que o filme de Sol de Carvalho mostra a realidade da violência contra a mulher no país por vias invertidas, porque no filme é a mulher que mata o homem e não o contrário.

O problema é que a violência contra a mulher na maioria das vezes só acaba se constituindo em um acontecimento importante, digno de punição exemplar, quando a vitima é uma mulher das classes privilegiadas e simbolicamente importantes, como o acontecido com as filhas de Samora Machel e Armando Guebuza.

A cultura patriarcal, como bem mostrou Diop (2015) e Santos (2011), têm suas raízes em um tempo distante e pode ser "rastreada" em vários espaços do planeta. Ela atravessa tanto a cultura ocidental, quanto as culturas africanas, indígenas, hindus, pré-colombianas e islâmicas. A sua prática tem sido "amenizada", sobretudo, no Ocidente, a partir do momento em que a mulher começou a trabalhar não apenas no espaço do $\operatorname{lar}^{7}$. Nesse aspecto, o advento da estruturação capitalista, a partir da primeira Revolução Industrial, permitiu a autonomia econômica da mulher, que passou

\footnotetext{
${ }^{7} \mathrm{~A}$ dupla jornada de trabalho, e às vezes, tripla, ainda é uma constante na vida da maioria das mulheres trabalhadoras.
} 
a ter a possibilidade de gerir sua vida e fazer escolhas. Mesmo assim, há disparidades salariais importantes e pequena intervenção na política, ou seja, a participação da mulher nas esferas de poder político e econômico ainda está muito longe de ser paritária.

A cultura patriarcal tão arraigada no tecido das diversas sociedades acaba sofrendo "adaptações", no decorrer do tempo, teimando em subjugar as mulheres, sendo a violência uma de suas cruéis facetas, que, conforme se discutiu no decorrer desse trabalho, tem convergido para a subalternização da mulher e a perpetuação do patriarcado, enquanto substrato das desigualdades inscritas nas relações entre homens e mulheres.

\section{CONSIDERAÇÕES FINAIS}

O cinema africano, ainda pouco difundido nos circuitos europeus e até frequentemente marginalizado nos próprios países africanos, tem revelado uma visão de seus produtores, como já foi dito, sobre as suas próprias sociedades. A partir de Ousmane Sembène ${ }^{8}$, partidário da ideia de que um povo que não fala por si está fadado a desaparecer, o cinema realizado na África tem contribuído para quebrar os frequentes estereótipos estabelecidos em relação ao povo e as sociedades africanas.

O filme Impunidades criminosas (IMPUNIDADES..., 2012), sem dúvida, põe em debate um tema relacionado à cultura patriarcal, polêmico e importante, como sempre faz o cinema de Sol de Carvalho. No filme $\mathbf{O}$ jardim de outro homem (O JARDIM..., 2006), também do cineasta, tal cultura é colocada em xeque, ao mostrar o modo pelo qual ela contribui para a difusão da AIDS em Moçambique e em outras partes da África.

\footnotetext{
${ }^{8}$ Com OusmaneSembène (1923/2007), pela primeira vez, o cinema trata de uma África vista a partir de si, para si e para o restante do mundo, sua cultura e seus dramas, por meio das lentes de um senegalês libertários, que antes de ser cineasta, foi soldado do exército francês, mecânico, estivador, sindicalista e escritor. A importância de Sembène não está apenas em ter sido um cineasta negro a fazer cinema na/e sobre a África, mas em apresentar um cinema ligado às grandes questões do povo senegalês, tanto nas relações com a França, como é o caso dos filmes Black girl (1966) e CampdeThiaroy(1987), quanto às próprias relações políticas internas, como é o caso de Xala(1975), Ceddo(1977) e Moolaadeé(2004). (OLIVEIRA; AVELAR; MIRANDA, 2013).
} 
Tratar de questões tão importantes como a questão da violência contra a mulher, e seus corolários, por meio do cinema é, de fato, uma oportunidade ímpar para que os espectadores possam olhar no espelho social de suas realidades, e possam funcionar como um "coro" do basta de violência contra a mulher não apenas em Moçambique, mas em todos os espaços de subjugação do sexo feminino ao masculino.

É necessário frisar que houve avanços no âmbito da legislação, em Moçambique, visando coibir a prática da violência contra a mulher, mas a persistência histórica da cultura patriarcal é tão forte que mesmo nas regiões do mundo em que ela foi oficialmente suplantada pela consagração constitucional da equidade entre os sexos, ou por legislações consideradas avançadas, as práticas quotidianas das instituições e das relações sociais continuam a reproduzir o preconceito e a desigualdade.

Em vários países de África, conforme Santos (2011), a prática da mutilação genital continua em voga. Na Arábia Saudita, as mulheres, não faz muito tempo, nem sequer tinham certificado de nascimento. No Irã, a vida de uma mulher vale metade da do homem num acidente de aviação; em tribunal, o testemunho de um homem vale tanto quanto o de duas mulheres; a mulher pode ser apedrejada até à morte em caso de adultério, prática, aliás, proibida na maioria dos países de cultura islâmica.

Assim, o filme de Sol de Carvalho para além de sua competente organização estética, que inclui, obviamente, a trilha sonora, a atuação dos personagens, bem como o trabalho de montagem, precisa ser divulgado, refletido, discutido como filme que é e como obra que acrescenta um contributo social relevante ao fazer refletir sobre a violência contra a mulher e toda a violência que a prática da desigualdade de poder gera entre homens e mulheres.

\section{REFERÊNCIAS}

BOURDIEU, Pierre. Las formas del capital. In:BOURDIEU, Pierre.Poder, derecho y clasessociales.Bilbao: Editorial Desclée De Brouwer, 2000.

IMPUNIDADES criminosas. Direção: Sol de Carvalho. Portugal, Moçambique: [s.n.], 2012. 74 min. Gênero: drama. Classificação. 14 anos. 
O JARDIM de outro homem. Direção: Sol de Carvalho. Moçambique, Portugal, França. 2006. 80 min. 14 anos.

CHEVALIER, Jean; GHE ERBRANT, Alain. Dicionário de símbolos: mitos, sonhos, costumes, gestos, formas, figuras, cores, números. Rio de Janeiro: José Olympio Editora, 1982.

CHIZIANE, Paulina Nicketche: uma história de poligamia. São Paulo: Companhia das Letras, 2004.

CUNHA, Bárbara Madruga da. Violência contra a mulher, direito e patriarcado: perspectivas de combate à violência de gênero. In: JORNADA DE INICIAÇÃO CIENTÍFICA DE DIREITO DA UFPR, 26, 2014, Curitiba. Anais [...]. Curitiba:UFPR, 2014. Disponível em: http://www.direito.ufpr.br/portal/wpcontent/uploads/2014/12/Artigo-B\%C3\%A1rbara-Cunha-classificado-em-7\%C2\%BAlugar.pdf. Acesso em: 13 abr. 2017.

DIOP, C. A. Unidade cultural da África negra: esferas do patriarcado e do matriarcado na antiguidade clássica. Lisboa: Pedago, 2015.

VIOLÊNCIA contra mulheres em Moçambique preocupa ONU-Mulheres. Folha de Maputo, Maputo, 03 out. 2010. Disponível em:

http://www.folhademaputo.co.mz/pt/noticias/nacional/violencia-contra-mulheres-emmocambique-preocupa-onu-mulheres/. Acessoem: 10 abr. 2017.

HALL, Stuart. The work of representation. In: HALL, Stuart (Org.) Representation: cultural representation and cultural signifying practices. London/Thousand Oaks/New Delhi: Sage/Open University, 1997.

KWONONOKA, Américo. A unidade cultural da África Negra: uma reflexão de grande alcance teórico e metodológico.Revista Mulemba: revista angolana de Ciências Sociais, Luanda, v. 5, n. 9, p. 493-499, 2015. Disponível em: http://mulemba.revues.org/434. Acesso em: 20 fev 2017.

MIRANDA, Maria Geralda de. Cinema africano em foco: entrevista com o cineasta Sol de Carvalho. Revista Mulemba: revista científica, Rio de Janeiro, v.12, n. 1, p. 21- 28, jul./dez. 2015. Disponível em:

https://revistas.ufrj.br/index.php/mulemba/article/view/5020. Acesso em: 13 maio 2017.

VIOLÊNCIA DOMÉSTICA é desrespeito de regras elementares dos Direitos Humanos.Agencia Lusa, 01 março 2017. Disponível em:

http://observador.pt/2017/03/01/mocambique-violencia-domestica-e-desrespeito-deregras-elementares-dos-direitos-humanos/. Acesso em: 16 maio 2017. 
NUNES, Maria Teresa Alvarez. Género e cidadania nas imagens de história: estudos de manuais escolares e softwares educativos. Lisboa: Comissão para a Cidadania e Igualdade de Género, 2007.

OLIVEIRA, A. G.; AVELAR, K.; MIRANDA, M. G. "O Pedagógico Em O Jardim Do Outro Homem". Revista Mulemba-UFRJ. V.1, n. 9, pp. 9- 21, jul./dez. 2013 Disponível em: <https://revistas.ufrj.br/index.php/mulemba/article/view/4981/3648>. Acesso em: 12 fev. 2017.

SANTOS, Boaventura de Souza. As mulheres não são homens. Carta Maior: o portal da esquerda, 09 mar. 2011. Disponível em: https://www.cartamaior.com.br/?/Coluna/As-mulheresnao-sao-homens/19489. Acesso em: 20 fev. 2017.

SILVA, Marcel Vieira Barreto Silva. Cinema e literatura dramática: alguns pontos de vista sobre as linguagens teatral e cinematográfica. Graphos, João Pessoa. v. 9, n. 1, p. 35-43, jan./jul. 2007. Disponível em:

periodicos.ufpb.br/index.php/graphos/article/download/4710/3574. Acesso em: 28 fev. 2017.

SOUSA, Pedro Miguel Teixeira. O coro e a dimensão sociológica e coletiva da tragédia grega. Coimbra: EC/FLU, 2005.

TAELA, Kátia. Revisão da literatura sobre violência doméstica contra a mulher. Maputo: n'weti, 2006. Disponível em: http://www.iese.ac.mz/lib/PPI/IESEPPI/pastas/governacao/justica/artigos_cientificos_imprensa/violencia_domestica.pdf. Acesso em: 10 maio 2017.

TOMÁS, Adelino Esteves Tomás. A violência contra à mulher: um estudo de caso nas cidades de Maxixe e de Nampula. 2016. 305 f. Tese (Doutorado em Sociologia da Família) - Faculdade de Letras da Universidade do Porto em Sociologia, Universidade do Porto, Porto, 2016. Disponível em: https://sigarra.up.pt/faup/pt//pub_geral.pub_view?pi_pub_base_id=113302\&pi_pub_r 1_id=. Acesso em: 12 maio $201 \overline{7}$.

PINTO, Álvaro Vieira. O conceito de tecnologia. Rio de Janeiro: Contraponto, 2005.

VANOYE, Francis; GOLIOT-LÉTÉ, Anne. Ensaio sobre a análise fílmica. Campinas, SP: Papirus, 1994. 